\title{
Stroke Vignettes
}

\section{Cerebrovascular Diseases}

\section{Aneurysm and TIAs}

Carlo Dallocchio a, Carlo Buffa ${ }^{\mathrm{a}}$, Antonio Riva ${ }^{\mathrm{b}}$

a Dipartimento di Neurologia e Riabilitazione, Ospedale

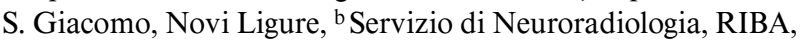

Torino, Italy

Figure 1a, b presents an MR angiography of the brain vessels demonstrating a voluminous fusiform aneurysm of the basilar artery. Its length is $5 \mathrm{~cm}$ and $2.5 \mathrm{~cm}$ in diameter; vertebral arteries can be identified inside. In proximity of the aneurysm top we can recognize the dolichoectactic basilar artery where the superior cerebellar and posterior cerebral arteries originate; circulation in both carotids is normal.

This MR angiographic picture belongs to a 76-year-old hypertensive woman, without history of neurological disorders. She developed TIAs (duration was $2 \mathrm{~h}$ both times) 5 months and 3 weeks
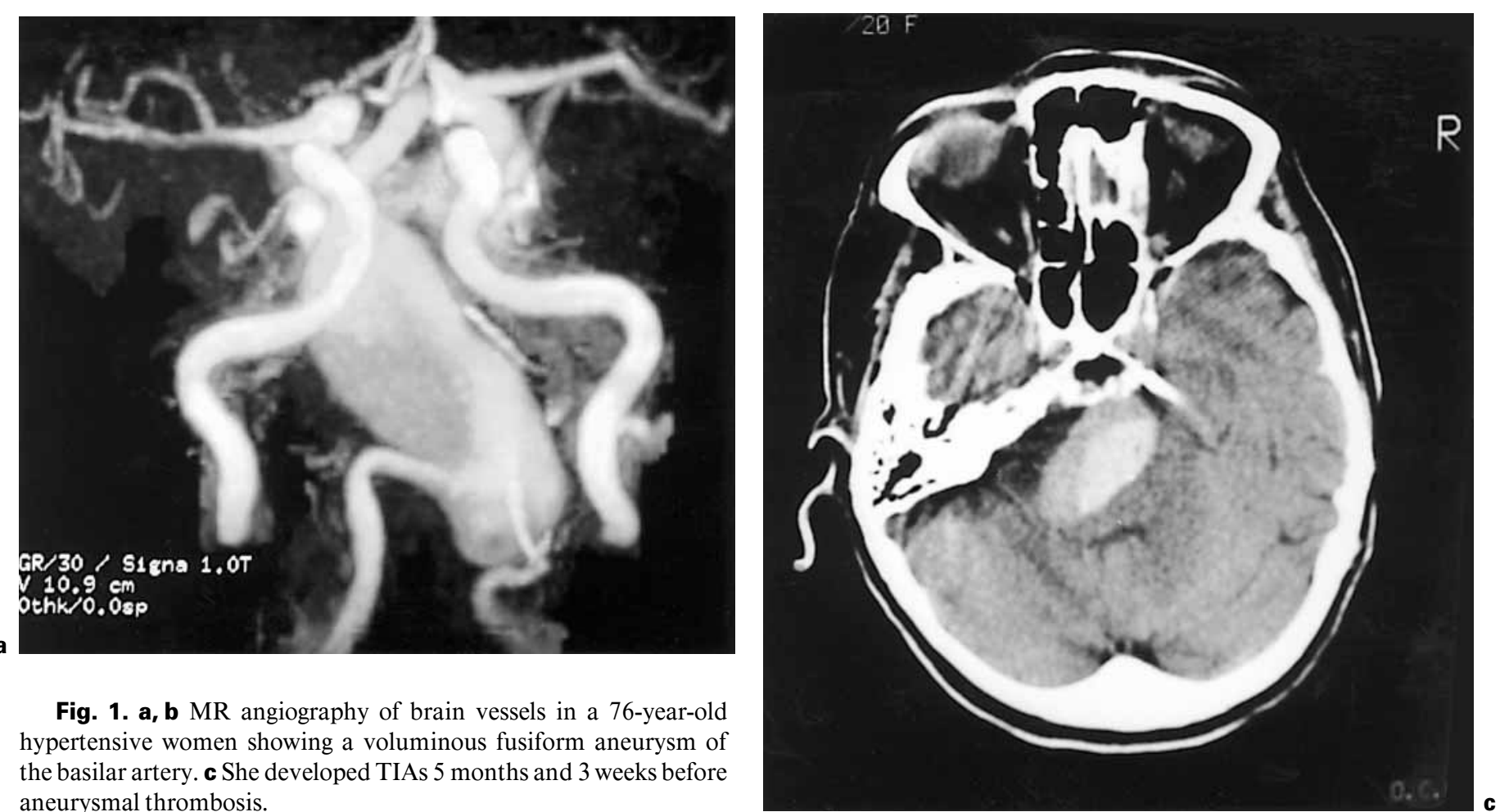

Fig. 1. a, b MR angiography of brain vessels in a 76-year-old hypertensive women showing a voluminous fusiform aneurysm of the basilar artery. $\mathbf{c}$ She developed TIAs 5 months and 3 weeks before aneurysmal thrombosis.

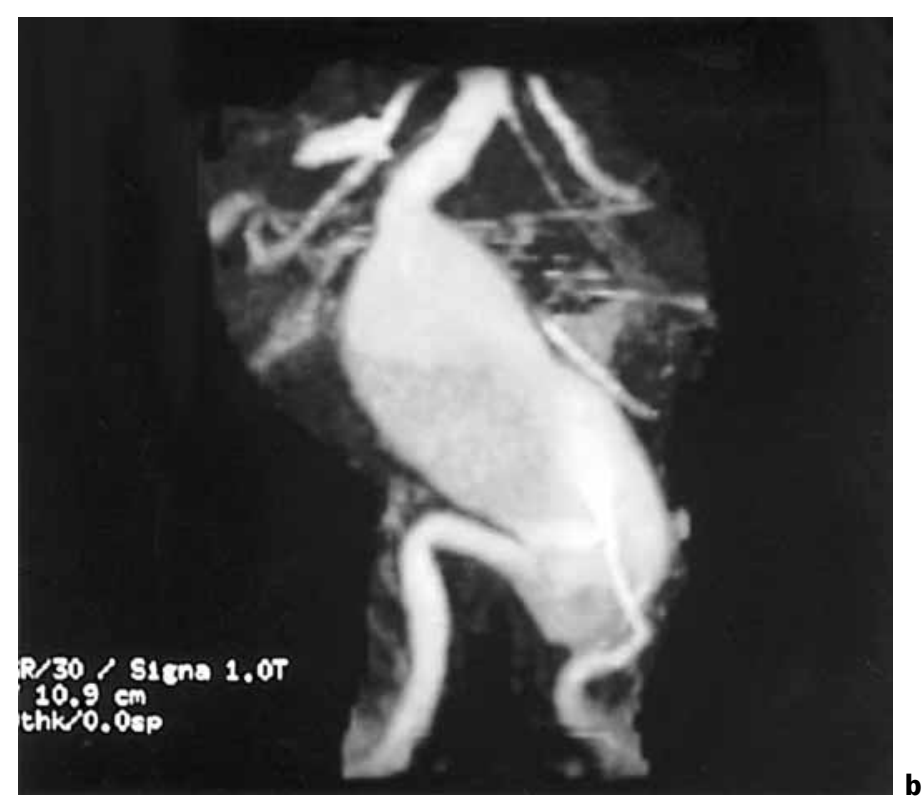

\section{KARGER}

Fax +4161306 1234

E-Mail karger@karger.ch

www. karger.com
(C) 1998 S. Karger AG, Basel

This article is also accessible online at:

http://BioMedNet.com/karger 
before aneurysmal thrombosis (fig. 1c). TIAs features included: dysarthria, vertigo, confusion, right arm weakness, diplopia and ataxia. She never had headache. Clinical signs were typical of vertebrobasilar territory stroke. Brain CT/MRI did not show any cerebral infarct.

Ischemic posterior circulation stroke in patients with fusiform vertebrobasilar aneurysms has been described in various articles [13]. This kind of aneurysm could cause posterior circulation infarcts (brainstem stroke in particular) by intraluminal thrombus, local embolism, atherosclerosis and obstruction of paramedian penetrating vessels [4]. It seems that intracranial arterial dolichoectasia is associated with higher rates of stroke recurrence [5].

\section{References}

1 Bogousslavsky J, Regli F, Maeder P, Meuli R, Nader J: The etiology of posterior circulation infarcts: A prospective study using magnetic resonance imaging and magnetic resonance angiography. Neurology 1993;43: $1528-1533$.

2 Echiverri HC, Rubino FA, Gupta SR, Gujrati M: Fusiform aneurysm of the vertebrobasilar system. Stroke 1989;20:1741-1747.

3 Wijdicks EF: Giant fusiform aneurysm presenting as fatal artery occlusion. Mayo Clin Proc 1997;72:437-439.

4 Pessin MS, Chimowitz MI, Levine SR, Kwan ES, Adelman LS, Earnest MP, Clark DM, Chason J, Ausman JI, Caplan LR: Stroke in patients with fusiform vertebrobasilar aneurysms. Neurology 1989;39:16-21.

5 Ince B, Petty GW, Brown RD, Jr, Chu CP, Whisnant JP: Dolichoectasia of intracranial arteries in patient with ischemic stroke: A population-based study. Neurology 1997;48(suppl 2):155.

\section{Infarction of the Medullary Pyramid with Hemiparesis Including the Face}

\section{S.P. Claus, L.J. Kappelle, L.M.P. Ramos, J. van Gijn}

University Department of Neurology, Utrecht, The Netherlands

A 71-year-old male, on getting up in the morning, experienced weakness of the right arm and leg. Examination confirmed a right hemiparesis which included the lower face. There were no other deficits. Axial MR imaging ( $T_{2}$, TSE) showed a hyperintense lesion located in the left ventral part of the medulla corresponding to an infarct in the medullary pyramid. Antegrade blood flow was established in both vertebral arteries on duplex investigation.

In the past, 5 other patients have been diagnosed with infarction of the medullary pyramid in whom contralateral hemiplegia included weakness of the lower half of the face. The explanation must be that some fibers projecting to the nucleus of the facial nerve do not cross the midline until they have descended to the level of the medulla, from where they loop upward to the contralateral pontine tegmentum. Such recurring fibers have indeed been found by the neuroanatomist Kuypers. The facial weakness is more marked as the lesion is higher in the medulla, where most of these fibers cross.

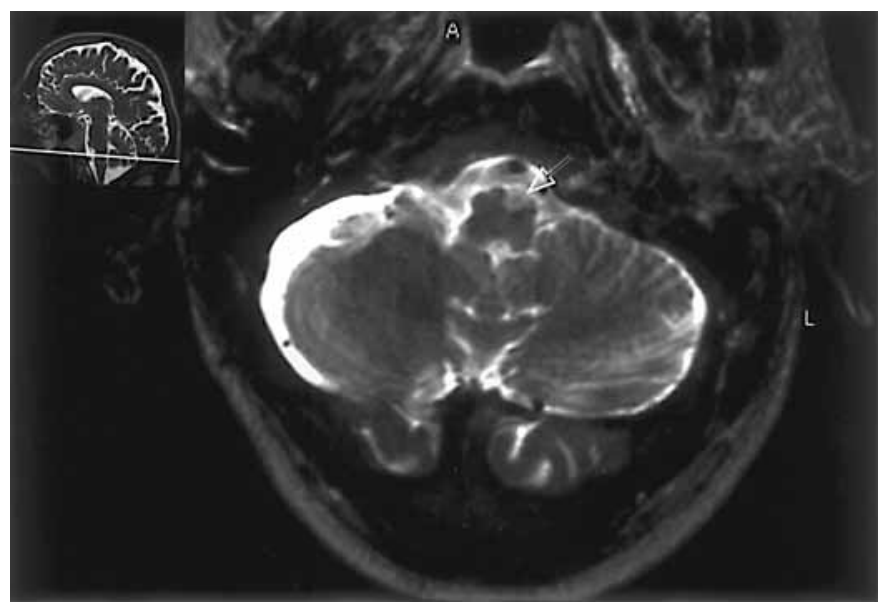

